\title{
A Time-Comparison Circuit in the Electric Fish Midbrain. II. Functional Morphology
}

\author{
Catherine E. Carr, ${ }^{*}$ Leonard Maler, $\dagger$ and Barbara Taylor $\ddagger$ \\ *Neurobiology Unit. Scripps Institution of Oceanography, UCSD, La Jolla, California 92093, \\ tDepartment of Anatomy, School of Medicine, Faculty of Health Sciences, University of Ottawa, \\ Ottawa, Ontario K1N 9A9, Canada, and łDepartment of Biology, UCSD, La Jolla, California 92093
}

The weakly electric fish Eigenmannia is able to detect temporal disparities as small as $\mathbf{4 0 0}$ nsec between two signals from different parts of the body surface (Carr et al., 1986). The elements of this time-comparison circuit have been identified by EM reconstruction of its component cells.

Information about the timing of the zero-crossing of signals on each area of the body surface is coded in phase-coder receptors, a subset of tuberous electroreceptors. Electroreceptors on the body surface are innervated by primary afferents with their central termination on the spherical cells of the medullary electrosensory lateral line lobe. These cells project to lamina VI of the midbrain torus, a structure similar to the inferior colliculus. Afferents entering lamina VI form a very restricted terminal arbor in which they synapse on the three cell types of this lamina. Each afferent makes gap-junction synapses on one or two giant cell somata and morphologically mixed synapses on the distal dendrites of two types of small cell. The afferent terminals thus encode the timing of the electric signal on a local patch of the body surface, forming a somatotopic map of the body surface in lamina VI.

The giant cells are adendritic and their axonal arbor is such as to distribute timing information originating from one part of the body surface throughout lamina VI, so that each region of lamina VI receives information about the timing of zero-crossings from the entire body surface from giant cells, as well as information from a local portion of the body surface from the afferent terminals. The giant cells terminate exclusively on the cell bodies of the small cells of lamina VI, shown to be sensitive to small temporal disparities by Heiligenberg and Rose (1985). Thus, each small cell receives a single synapse on its soma from a giant cell that conveys phase-coding information from some portion of the body surface and receives local phase-coding input onto its dendrites from spherical cell afferents.

The sensitivity of the small cells to temporal disparities appears to be conferred by their segregation of inputs from two different parts of the body surface onto dendrites and soma, respectively. We propose that the dendritic input acts as a delay line, and the small cell fires maximally when the inputs from the dendrites and the giant cell input onto the soma coincide.

Behavioral experiments have shown that the weakly electric fish Eigenmannia is able to detect temporal disparities of less than $0.5 \mathrm{msec}$ between two signals from different areas of its body

Received July 10, 1985; revised Nov. 18, 1985; accepted Nov. 21, 1985.

We gratefully acknowledge the advice and assistance of J. Dye, B. Ellis, W. Heiligenberg, N. Holland, G. Kennedy, and B. Mathiesson. This work was supported by NSF Grant BNS/6-20761 to W. Heiligenberg, a Harry Crossley bursary to C.E.C., and MRC Grant MI6027 to L.M.

Correspondence should be addressed to C. Carr, Department of Biology, 21676, California Institute of Technology, Pasadena, CA 91125.

Copyright (Q) 1986 Society for Neuroscience $0270-6474 / 86 / 051372-12 \$ 02.00 / 0$ surface. These temporal disparities occur when the animal's own electric organ discharge is differentially contaminated by an interfering electric organ discharge from a neighboring fish (Bullock et al., 1972; Carr et al., 1986; for reviews, see Heiligenbcrg, 1977, 1980, 1983). Sensitivity to these temporal disparities emerges in the small cells of lamina VI of the midbrain torus semicircularis dorsalis (hereafter referred to as the torus), a nucleus similar ${ }^{1}$ to the inferior colliculus (Heiligenberg and Carr, 1983; Heiligenberg and Rose, 1985). Lamina VI of the torus receives information about the timing of zero-crossings ${ }^{2}$ from different parts of the body surface through the phase-coding system - see Figure 1 (Carr et al., 1986). Phase-coding electroreceptors on the body surface are innervated by phase-coding primary afferents that synapse on spherical cells of the electrosensory lateral line lobe of medulla. Spherical cells relay this phase-coding signal to the midbrain torus and synapse on the giant and small cell types of lamina VI. The small cells respond to specific differences in timing of the zero-crossing of these signals from different regions of the body. The mechanism underlying this sensitivity to temporal disparities is of general relevance to a number of sensory systems, such as directional hearing, and it is notable in its accessibility in Eigenmannia.

The attempt to correlate circuit structure with function is a complex undertaking in the vertebrate brain. Many of these difficulties are reduced in lamina VI. It has a single well-characterized type of input, three cell types, and a specific and unique function, the evaluation of differences in phase (or the timing of zero-crossings) between signals from different parts of the body surface. Lamina VI is also functionally close (two electrotonic synapses) to its primary sensory input. Intracellular recording and labeling with HRP have been used to identify the site of the phase comparisons in the electric fish torus, followed by ultrastructural reconstruction of the labeled elements.

\section{Materials and Methods}

Three techniques were used to label cells and thus identify the components of this circuit. These were a variation of the Golgi-Kopsch technique (Carr and Maler, 1985; Riley, 1979) and intracellular injection of HRP and Lucifer yellow. Labeled cells were also processed for light microscopy (Carr et al., 1986).

Normal material for electron microscopy was prepared following the protocol of Maler et al. (1981), and tissue for HRP-EM was processed according to the protocol of Wilson and Groves (1980). After intracel-

\footnotetext{
The sensory midbrain of weakly electric fish contains separate representations of the auditory, mechanoreceptive lateral line and electroreceptive senses. There is no evidence, with the loss of the lateral line senses among some amphibians and all amniotes, that the central neural pathways and nuclei are retained and used to process information from other sensory modalities (Boord and McCormick, 1984). The relationship of the dorsal torus semicircularis to the inferior colliculus therefore may not be accurately described at present.

Zero-crossings are the time at which the voltage across the skin changes from inside-positive to outside-positive.
} 


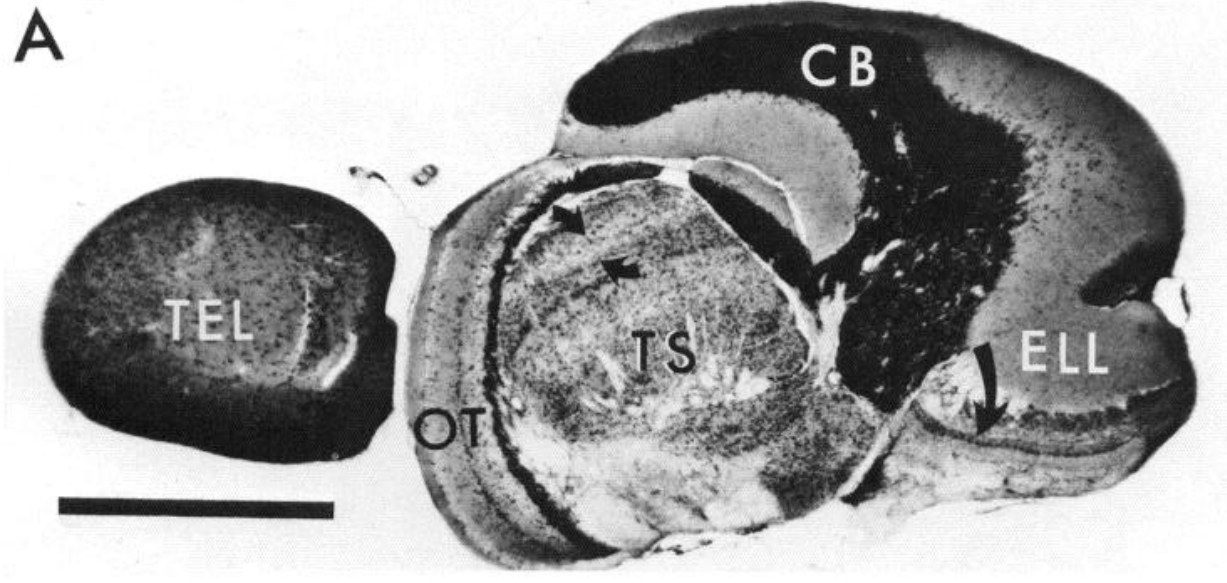

B

MIDBRAIN:

TORUS LAMINA 6

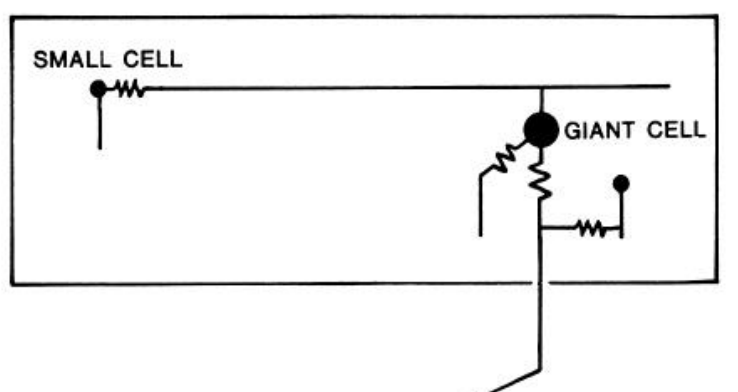

MEDULLA:

ELECTROSENSORY LATERAL LINE LOBE

ANTERIOR LATERAL LINE NERVE

ALLN GANGLION

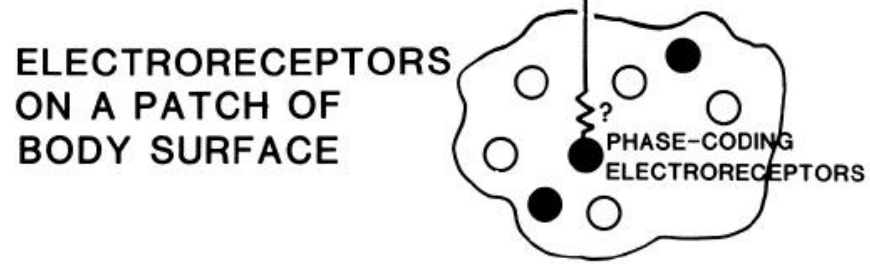

Figure 1. The phase-coding system of Eigenmannia. A, Sagittal section of the Eigenmannia brain reveals the elements of the phase-coding system. Arrows mark the spherical cell layer of the electrosensory lateral line lobe and lamina VI of the torus. $C B$, Cerebellum; $E L L$, electrosensory lateral line lobe; $T E L$, telencephalon; $O T$, optic tectum; TS, dorsal torus semicircularis. Bar, $1 \mathrm{~mm}$. $B$, Diagram of the phase-coding system. Electroreceptors on the body surface are of two types, phase-coding (black symbols) and amplitude-coding (open symbols). Phase-coding electroreceptors are innervated by primary afferents with cell bodies in the ganglion of the anterior lateral line nerve, and central terminations on the somata of the spherical cells of the electrosensory lateral line lobe. Spherical cells relay phase-coding information to lamina VI of the midbrain torus, where they synapse on the giant and small cell types of that lamina. Resistor symbols denote electrotonic synapses. lular injection of HRP and survival of a few hours, the fish was transcardially perfused with saline followed by $2 \%$ paraformaldehyde $/ 2 \%$ glutaraldehyde. The brain was removed, postfixed for an hour and then sectioned on a vibratome (40-60 $\mu \mathrm{m}$ thick). Despite excellent fixation, intact myelin was rare in these sections; the damage may be attributed to the vibratome or the room-temperature HRP reaction. After HankerYates reaction as modified by Finger (Bell et al., 1981), the wet sections were inspected for HRP labels under the microscope. Those sections that contained processes of interest (terminal fields rather than axons alone) were osmicated and embedded for EM sectioning. The density of the reaction product may be readily controlled by the degree of osmication.

The embedded sections were either serially sectioned onto single-hole Formvar-coated grids or cut into $3 \mu \mathrm{m}$ semithin sections that were again inspected for labels of interest. Labeled processes were then drawn with the camera lucida before the semithin section was reembedded for ul- 

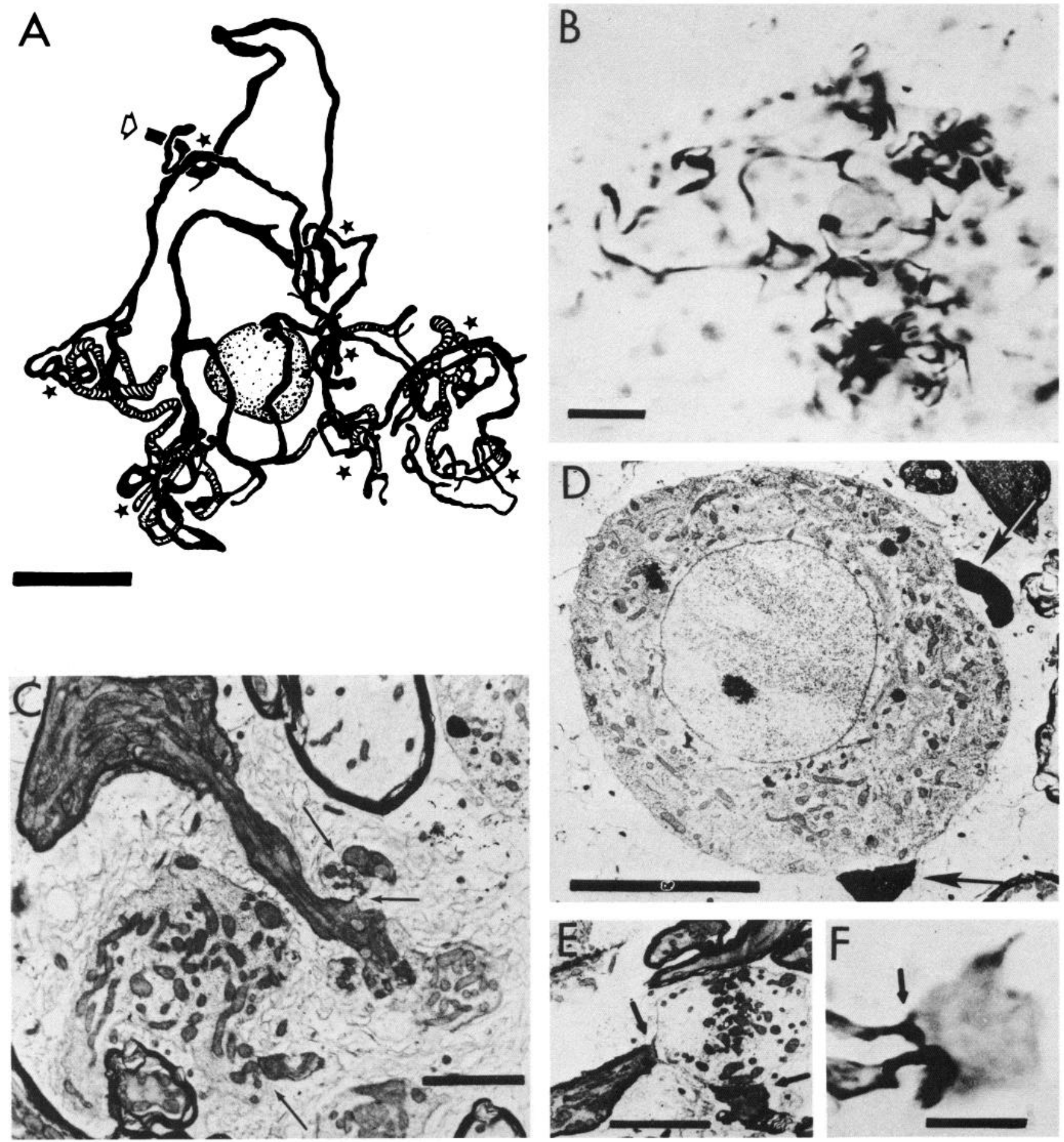

Figure 2. Spherical cell axons from the electrosensory lateral line lobe terminate in lamina VI on two targets, the giant cell and the distal dendrites of small cells. A. Camera lucida drawing on the terminal arbor in lamina VI of an afferent to the torus. Shaded portions permit visualization of overlapping knots of afferent terminals. Ultrastructural analyses have shown that each knot $(\star)$ participates in at least one synaptic island. The open arrow indicates the incoming axon. Bar, $20 \mu \mathrm{m}$. B. Photomicrograph of afferent terminals surrounding a giant cell soma. Note the knots of terminals distant from the soma. Bar, $20 \mu \mathrm{m}$. $C$, An HRP-labeled afferent entering a synaptic island, at which point it loses its myelin and forms synapses (arrows) on the mitochondria-rich dendrite that enters at lower left. Bar, $2 \mu \mathrm{m}$. D. Giant cell soma with two HRP-labeled afferent terminals (arrows). Bar, $8 \mu \mathrm{m}$. E. HRP-labeled afferent axons synapsing (arrows) on a dendrite in a synaptic island. Note that they lose their myelin just before they form synapses. Bar, $4 \mu \mathrm{m}$. F, Light micrograph of an HRP-filled afferent forming two synapses (arrow) on a giant cell soma. Bar, $20 \mu \mathrm{m}$.

Figure 3. Morphology of giant cells. A, Camera lucida drawing of an HRP-filled giant cell, reconstructed from transverse sections to provide a dorsal view of the entire mediolateral view of lamina VI. Note all toral laminae are fused across the midline; i.e., the torus is a single midline 

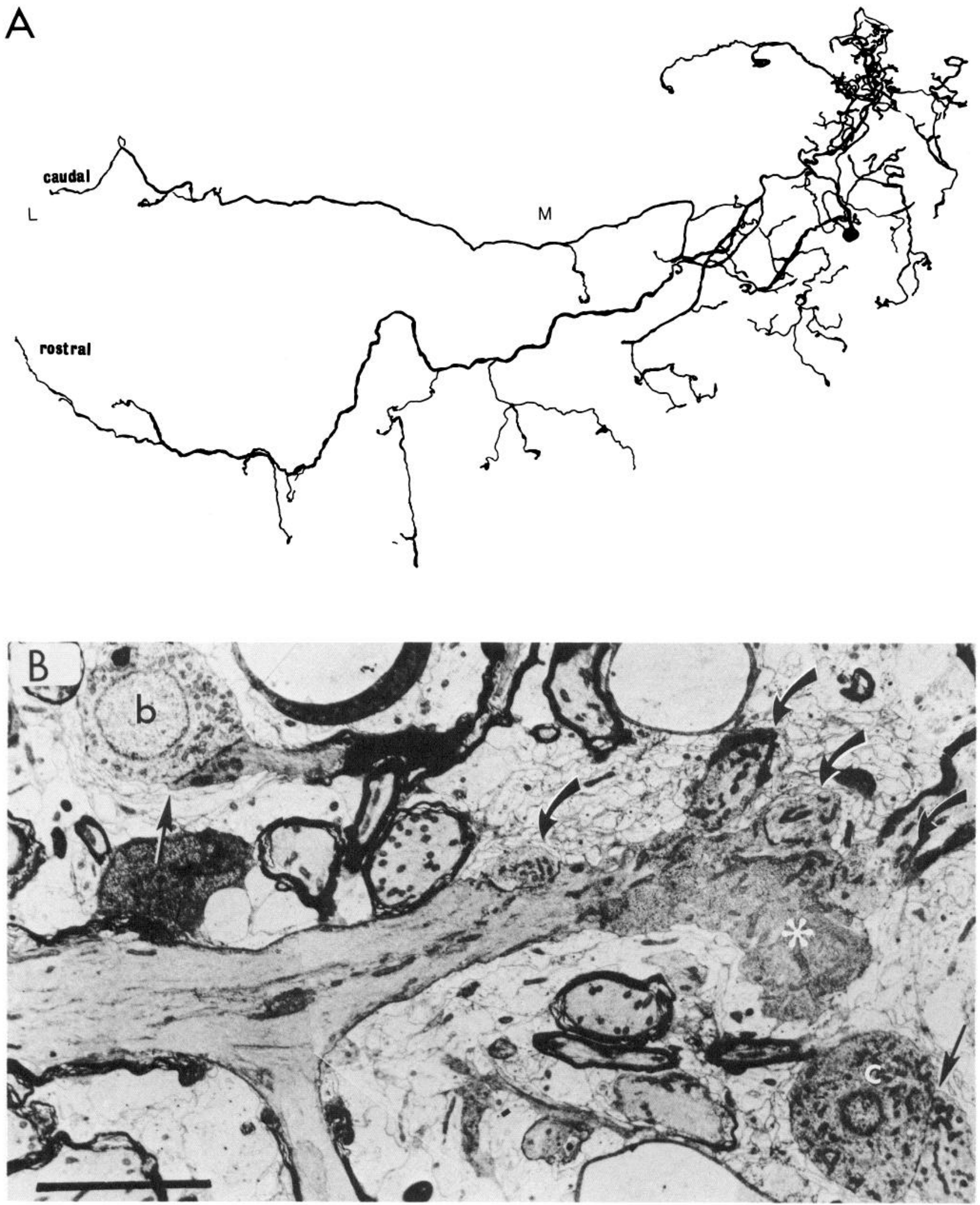

nucleus. The axons marked as rostral and caudal travel to the contralateral side of lamina VI and are actually separated by $1500 \mu \mathrm{m}$. Note the many terminal swellings on the axons. $M$, midline of lamina VI; $L$, lateral. Bar, $200 \mu \mathrm{m}$. $B$, Montage of the soma ( $\star$ ) and initial segment of the giant cell. Only a small portion of the soma remains in the section, but on it may be seen three afferent terminals, while another is found on the initial segment (curved arrows). The initial segment has a characteristic dense coating until the onset of myelination. The first branch off the main axon trunk occurs within $10 \mu \mathrm{m}$ of the soma. Also in this montage are two small cells, one in the upper left and the other at lower right. They each receive a synapse from other giant cells (arrows). The small cell at left $(b)$ is type VIb, characterized by pale cytoplasm, and the small cell at right $(c)$ is the second type, VIc, with darker cytoplasm. Bar, $5 \mu \mathrm{m}$. 
timate serial thin sectioning. Inspection of serially sectioned material under the EM allowed us to follow the course of labeled processes up to their synaptic contacts. The presence of particular intracellular features that characterize a given class of neurons enabled us to identify the cell type contacted by the labeled synapse (Carr et al., 1983).

\section{Results}

Information about the timing of electrosensory signals from different parts of the body surface is processed by the phasecoding system (Scheich et al., 1973), which is specialized for the rapid and accurate transmission of this form of information. A previous paper (Carr et al., 1986) detailed the behavioral limits and physiological adaptations of this system and suggested that the improvement in accuracy in the phase-coding system from receptor to midbrain torus may in part be due to spatial convergence. The data below provide a morphological substrate for the sensitivity of the phase-coding system to small temporal disparities that emerge in lamina VI of the midbrain torus.

\section{Phase-coding afferents}

Lamina VI receives information about the timing of zero-crossings (phase) from the entire body surface, transmitted by primary afferents of the phase-coding type, through gap junctions to the spherical cells of the three tuberous zoncs of the ipsilateral medullary electrosensory lateral line lobe (Fig. 1; Carr et al., 1982; Heiligenberg and Dye, 1982; Maler et al., 1981). These spherical cells project through thick myelinated axons to the contralateral lamina VI of the midbrain torus. They synapse on the cell bodies of a singlc class of giant (20-40 $\mu \mathrm{m}$ soma) phasecoding interneurons. All three electrosensory lateral line lobe maps converge on a single somatotopic map in the torus (Carr et al., 1981; Heiligenberg and Bastian, 1984; Maler et al., 1982).

Intracellular recording and filling of the spherical cell axons of the electrosensory latcral linc lobe demonstrate that each forms a dense basket of terminals around the soma of a single giant cell in the torus (Fig. 2, $A, B, D$ ). What degree of convergence exists from lateral line lobe to torus? There are approximately 380 giant cells in lamina VI, and 1200-1500 spherical cclls from both electrosensory lateral line lobes. The mean convergence is therefore 4:1 (Carr et al., 1986). A similar rate of convergence can be inferred from ultrastructural studies. Spherical cell axons injected with HRP show obvious boutons on giant cell somata, which may be counted at the LM level (Fig. $2 F$ ). Seven labeled afferents were examined; numbers of boutons per soma ranged from 1 to 8 (mean $\pm \mathrm{SD}=4 \pm 2.2$ ). Examination of serial sections through giant cell somata at the ultrastructural level yielded counts of a total of 12 and 15 synapses per cell. In one unusual case, an HRP-filled afferent synapsed on two neighboring giant cells. Two synapses were found on one giant cell (Fig. $3 F$ ), and four on its neighbor, $20 \mu \mathrm{m}$ away. In serial section through two other afferent terminals, terminals were observed on a single giant cell in each case. In addition, observations of seven labeled afferents with the LM showed terminals on a single giant cell in each case

These estimates confirm the measures of convergence in the earlier paper (Carr et al., 1986), indicating that giant cells receive inputs from three to four spherical cells. Thus, each giant cell would have a receptive field somewhat larger than the receptive fields in the electrosensory lateral line lobe. This convergence at both the nerve-lateral line lobe and the lateral line lobe-torus level may partially account for the improvement in timing accuracy or decrease in jitter with the progression from primary afferent to midbrain torus (Carr et al., 1986).

The phase-coding spherical cell afferents form larger clubshaped endings on the somata of lamina VI giant cells, losing their myelin very close to the terminal (Figs. 2D, 4C). These terminals are very similar to those made by the phase-coding primary afferents onto the spherical cells in the medulla, the source of these afferents (Maler et al., 1981). The terminals contain a dense matrix of mitochondria, microtubules, and neurofilaments, as well as a large number of vesicles, dense-core vesicles, and coated vesicles, none of which appears to be associated with the presynaptic membrane. These synapses may be purely mediated by gap junctions. The spherical cell afferents make extensive contact with the giant cell somata, the contact zone consisting of desmosomes, gap junctions, and unspecialized appositions. The gap junctions are long, rather than punctate, and asymmetric, with a dense region made up of globular subunits up to $30 \mathrm{~nm}$ into the postsynaptic side (Fig. $4 E$ ). That part of the giant cell that is not covered with afferent terminals is wrapped in glial processes.

Phase-coding spherical cell afferents do more than synapse on the somata of giant cells. The majority of the synapses made by these afferents are in the neuropil of lamina VI near their target giant cell, in the "synaptic islands" created by the interdigitation of small cell dendrites and axon terminals (Figs. $2 C$, $E ; 6)$. In serial sections through the basket of terminals formed by an afferent, it was found to participate in approximately 25 synaptic islands. This form of connection appears central to the ability of lamina VI to perform temporal discriminations, and will be discussed in detail below.

\section{Giant cells}

The giant cells of lamina VI are the largest (20-40 $\mu \mathrm{m}$ soma) cell type in the torus (Carr and Maler, 1985). They are all unipolar and adendritic; the axon has two or three large collaterals and a number of finer branches that arborize close to the soma.

Intracellular fills in the torus giant cells demonstrate that they have a characteristic morphology that enables them to convey phase information to almost every other part of lamina VI (Fig. $3 A$ ). Lamina VI is somatotopically organized, with the head represented rostrally and trunk represented caudally. Giant cells with receptive fields on the dorsal surface of the fish's body surface are found medially in lamina VI, while those cells with receptive fields on the ventral surface are at the lateral edges of the lamina. Because of this somatotopic organization, the morphology of the giant cell is dependent on the part of the body from which it receives its input. All giant cells have two or more thick axon collaterals $(5-15 \mu \mathrm{m})$, at least one of which is contralateral, making a homotypic connection in the vicinity of its contralateral homologue and thus ensuring that timing information from equivalent but opposite sides of the body arrives in the same region of lamina VI. Giant cells in the more caudal torus, which receive their input from phase-coding spherical cells with receptive fields on the trunk, generally also send another contralateral axon to a more rostral (head) region of lamina VI, while rostrally situated giant cells send a second axon to the more caudal contralateral (trunk) region of lamina VI. As a rule, giant cells have at least one ipsilateral axon that is either rostrally or caudally directed, depending on the cell's location. The connections of these giant interneurons provide a substrate for the phase comparisons essential for the performance of the jamming avoidance response (Carr et al., 1986).

The giant cell somata are electron-dense due to the presence of large numbers of intracellular organelles, particularly mitochondria, lysosomes, the Golgi apparatus, and rough endoplasmic reticulum (Fig. 4). They are surrounded by several layers of glial processes that envelop the cell except where it receives afferent inpul. Many of the afferent terminals onto the soma are located close to the initial segment, which is long and thick with a prominent dense undercoating (Fig. $3 B$ ). The initial segment contains smooth endoplasmic reticulum and polyribosomes as well as the microtubules and neurofilaments found throughout the length of the axon. The axons of lamina VI range in size from 2 to $15 \mu \mathrm{m}$ in diameter (Fig. $4 D$ ). It has been possible to 

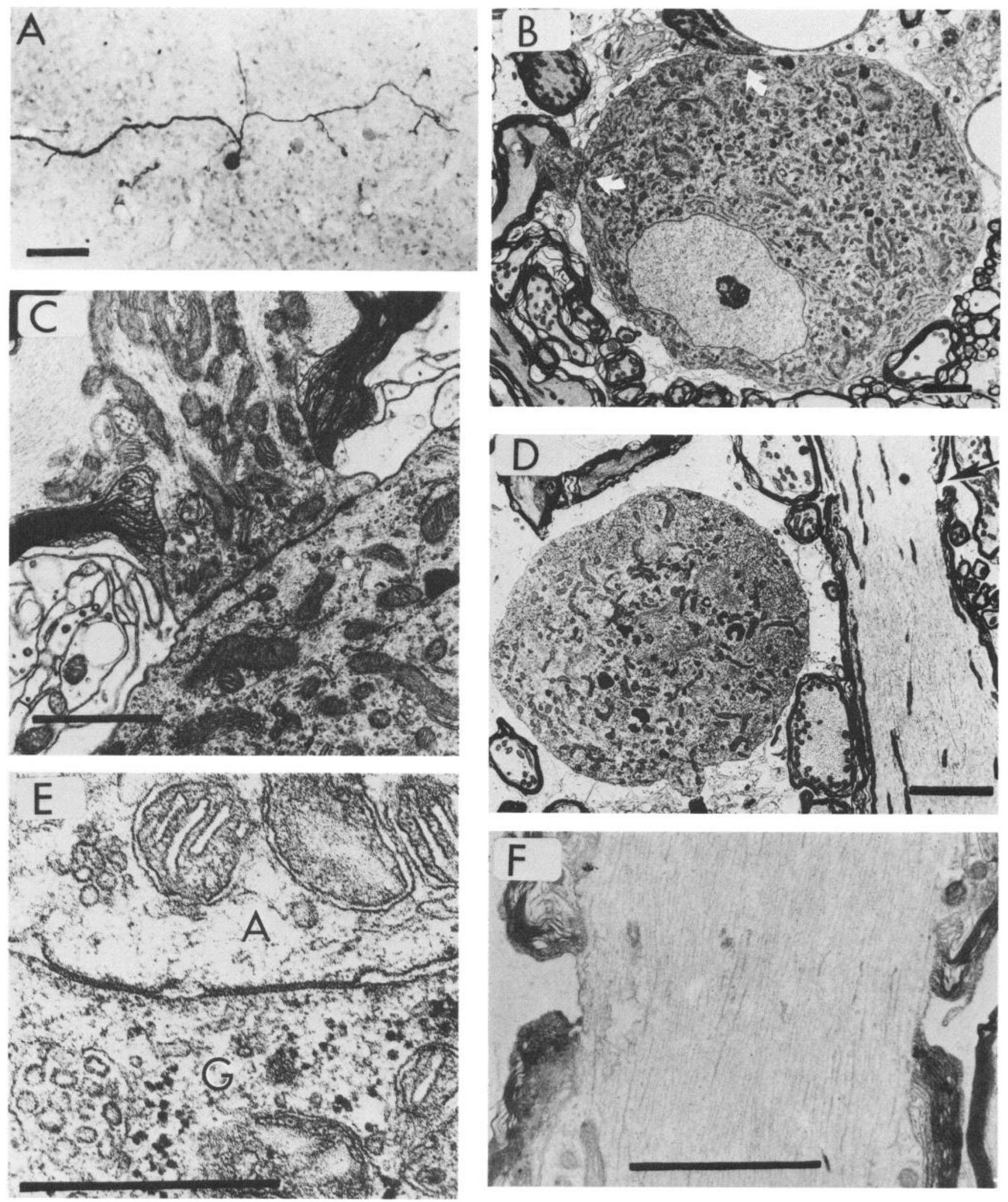

Figure 4. Giant cell morphology. A, Light micrograph of a portion of an HRP-labeled giant cell. Note the unipolar soma and thick axons. Bar, $100 \mu \mathrm{m}$. B. Giant cell soma with two afferent synapses (arrows). Note that the terminals lose their myelin within $1 \mu \mathrm{m}$ of the synapse. Bar, $2 \mu \mathrm{m}$. $C$, Afferent to giant cell synapse. Gap junctions alternate with desmosomal contacts. Bar, $1 \mu \mathrm{m}$. $D$, Giant cell with an adjacent axon containing a node (arrow). Bar, $3 \mu \mathrm{m}$. $E$, Details of the afferent $(A)$ to giant $(G)$ cell synapse. Bar, $0.5 \mu \mathrm{m}$. $F$, Node in a giant cell taxon. Bar, $2 \mu \mathrm{m}$. 
measure internodal distances in five cases; they ranged from 20 to $30 \mu \mathrm{m}$ (Fig. $4 F$ ).

The axons of giant cells form only one type of termination on the cell body of the small cells (Fig. 5). This connection may be observed even at the LM level, as heavy HRP fills of giant cells often produce transneuronally labeled small cell bodies (Triller and Korn, 1981) next to giant cell axon terminals (Fig. $5 C$ ). We used these appositions to estimate by light microscopy the number of synapses made by an individual giant cell. Every blind-ending axon close to a small cell soma was assumed to be a terminal and scored as a synapse. Elcven giant-cell fills were counted, yielding a mean of $88( \pm 15 \mathrm{SD})$ apparent synapses per cell. These connections were densest within a $300 \mu \mathrm{m}$ radius of the soma but were found throughout the giant cell arborization. These estimates were confirmed by ultrastructural observations of eight HRP-labeled giant cell terminals onto small cells both close to and far from the giant cell soma (Fig. $5 F$ ).

\section{Small cells}

Lamina VI contains two small cell types (Carr and Maler, 1985) both of which respond to small temporal disparities (Heiligenberg and Rose, 1985). They have somata of 6-12 $\mu \mathrm{m}$ diameter and are very numerous, scattered throughout the lamina and sometimes grouped in clusters of two to three cells (Fig. $5 \mathrm{~A}$ ). The small cells have two or four thin $(1 \mu \mathrm{m})$ smooth dendrites that leave the soma and form convoluted, enlarged endings some $10-40 \mu \mathrm{m}$ away. These may be seen in a Golgi-Kopsch preparation (Fig. 5, $A, D$ ). Ultrastructural studies show that these endings form the synaptic islands that are found throughout the neuropil of VI.

Although two types of small cell may be distinguished on physiological and ultrastructural grounds, and in Golgi impregnations, we have been unable to identify which physiological type correlates with which anatomical type. At the ultrastructural level, the first type is smaller and more electron dense than the other and contains a large number of mitochondria and profiles of rough endoplasmic reticulum. The second has fewer organelles and a larger nucleus (Fig. $5 B$ ). Their dendritic morphology is also slightly different, with the larger type possessing a more elaborate dendritic tree (Carr and Maler, 1985). Both small cell types possess a long thin initial segment, from 10 to $20 \mu \mathrm{m}$ in length, with a prominent dense undercoating.

Ultrastructural studies in lamina VI of HRP-labeled afferents and giant cells demonstrate that the small cells receive gap junction input onto their somata from giant cells (Fig. 5, $C, F$ ) and input from electrosensory lateral line lobe afferents onto their dendrites (Fig. 6).

Small cells all receive only one synapse from a giant cell onto their somata. This synapse has a distinct morphology; it is very large, and may indent into the cell body (Fig. 5C). The giant cell terminal loses its myelin very close to the soma of the small cell, and the large bouton has a wide area of contact with the small cell (Fig. 5, $C, E$ ). The terminal contains a large number of mitochondria, neurofilaments, and vesicles, and both gap junctions and chemical synapses are formed in a classic morphologically mixed synapse (Sotelo and Korn, 1978), although gap junctions predominate (Fig. $5 E$ ). In the junction area, the two apposed membranes often form double invaginations (Fig. $5 E$ ).

The dendrites of small cells are thin (less than $1 \mu \mathrm{m}$ ) and vary considerably in length (from 10 to $40 \mu \mathrm{m}$; Figs. $5 C$, 6). They form swellings and convoluted knots as large as $5 \mu \mathrm{m}$ at their terminal ends in association with the afferent terminals of incoming spherical cell axons (Figs. $2 C, E ; 6$ ). This structure is surrounded by numerous thin glial lamellae and has been termed a synaptic island after similar structures in the weakly electric pulse fish, Gymnotus carapo (Sotelo et al., 1975).

In the synaptic islands, both chemical and gap junction are found side by side, forming morphologically mixed synapses. Clusters of round vesicles are found against presynaptic densities, and the gap junction conforms to those described in the general literature (Sotelo and Korn, 1978) and in other Gymnotiformes specifically (Sotelo et al., 1975). The gap junction is the most common type observed in gymnotiform fish-see Fig. $4 E$ (Maler et al., 1981; Pappas et al., 1975; Sotelo and Llinás, 1972; Tokunaga et al., 1980), being asymmetric with an electron-dense region about $30 \mathrm{~nm}$ thick on the postsynaptic side.

An individual axon terminal and the dendrite of a small cell may form numerous synapses on one another (Fig. 6). The degree of intermingling of axonal and dendritic elements is considerable. Dense HRP fills of an afferent obscure the presynaptic details in a synapse but also display an unusual feature of these afferent terminals. The terminal may thin to a flat sheet, about $100 \mathrm{~nm}$ thick, and wrap about the dendrite (Fig. 6D). Such appositions do not appear to contain either synapses or tight junctions. Thus, in addition to the glial lamellae that surround the synaptic islands, the afferent terminal itself may add electrical isolation. The glial wrappings may also be well developed, as in the rare case of a synaptic island surrounded entirely by myelin, so as to form a cylinder with a myelinated axon entering on one side and a dendrite exiting on the other.

Each small cell has from two to six dendrites, each of which receives input from a phase-coding afferent. In some cases, an afferent may contact more than one dendrite in a single synaptic island, and in one instance, two axons were observed to enter and synapse on one another, as well as on the dendrite in a synaptic island. The axoaxonic synapse had a similar form to the surrounding axodendritic synapses. It was not observed in a case with intracellular labeling, and consequently the identity of the two axon terminals is unknown.

\section{Discussion}

Rehavioral experiments have shown that Eigenmannia are able to perform correct jamming avoidance responses by comparing signals from different parts of their body surface (Heiligenberg, 1983). Use of the jamming avoidance response as a behavioral assay has shown that these fish detect temporal disparities between different parts of the body as small as $400 \mathrm{nsec}$ (Carr et al., 1986). The organization of lamina VI in the torus provides a morphological substrate for the temporal aspects of this behavior. The input from the phase-coding system to lamina VI giant cells and small cells yields a fast and accurate reflection of the timing of the zero-crossings of signals on the body surface (Carr et al., 1986), and the structure of the giant cell provides a morphological substrate for distributing the timing information about one part of the body to all regions of lamina VI. Similarly, the structure of the small cells permits the segregation and comparison of inputs representing different spatial origins. The elements of the time-comparison circuit are summarized in Figure 7. The structure of both the giant and small cells reflects their function.

Although the small cells receive a somatic gap junction contact from one giant cell, this does not drive them in a one-toone fashion, or even at a high rate (Heiligenberg and Rose,

Figure 5. Small cell morphology. $A$, Camera lucida drawing of a Golgi-Kopsch impregnation of the small cells of lamina VI. This lamina is pierced at regular intervals by columns of vertical neuropil $(v n)$. Bar, $50 \mu \mathrm{m}$. B, The two types of small cell in lamina VI. Type VIb, characterized by pale cytoplasm and a larger soma, is shown at bottom with a giant cell synapse. Type VIc, above, has darker cytoplasm and a vertically directed dendrite. 

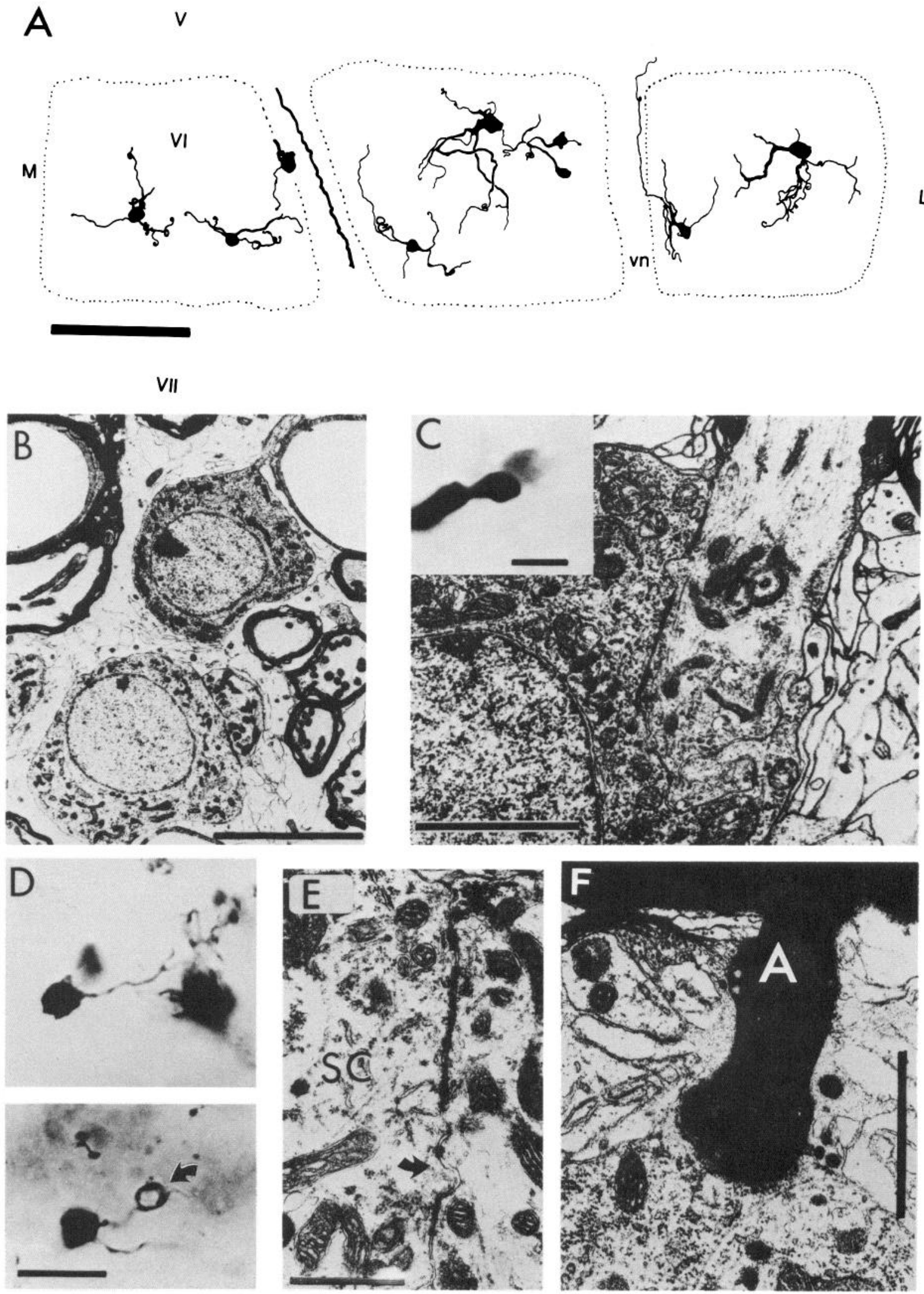

Bar, $5 \mu \mathrm{m}$. $C$, Giant cell to small cell synapses. The synapse indents deeply into the small cell body. Bar, $2 \mu \mathrm{m}$. Inset, This light micrograph of a heavily labeled giant cell terminal demonstrates the transneuronal filling of a small cell. Bar, $10 \mu \mathrm{m}$. $D$, Golgi-impregnated small cells. Note the thin dendrites, and at bottom, the curl (arrow) made by the dendrite as it presumably wraps around an axon terminal. Bar, $10 \mu \mathrm{m}$. $E$, Details of the giant cell to small cell (SC) synapse. Note the double invaginations (arrow). Bar, $0.5 \mu \mathrm{m}$. F, HRP-labeled giant cell synapsing on a small cell. Bar, $1 \mu \mathrm{m}$. 

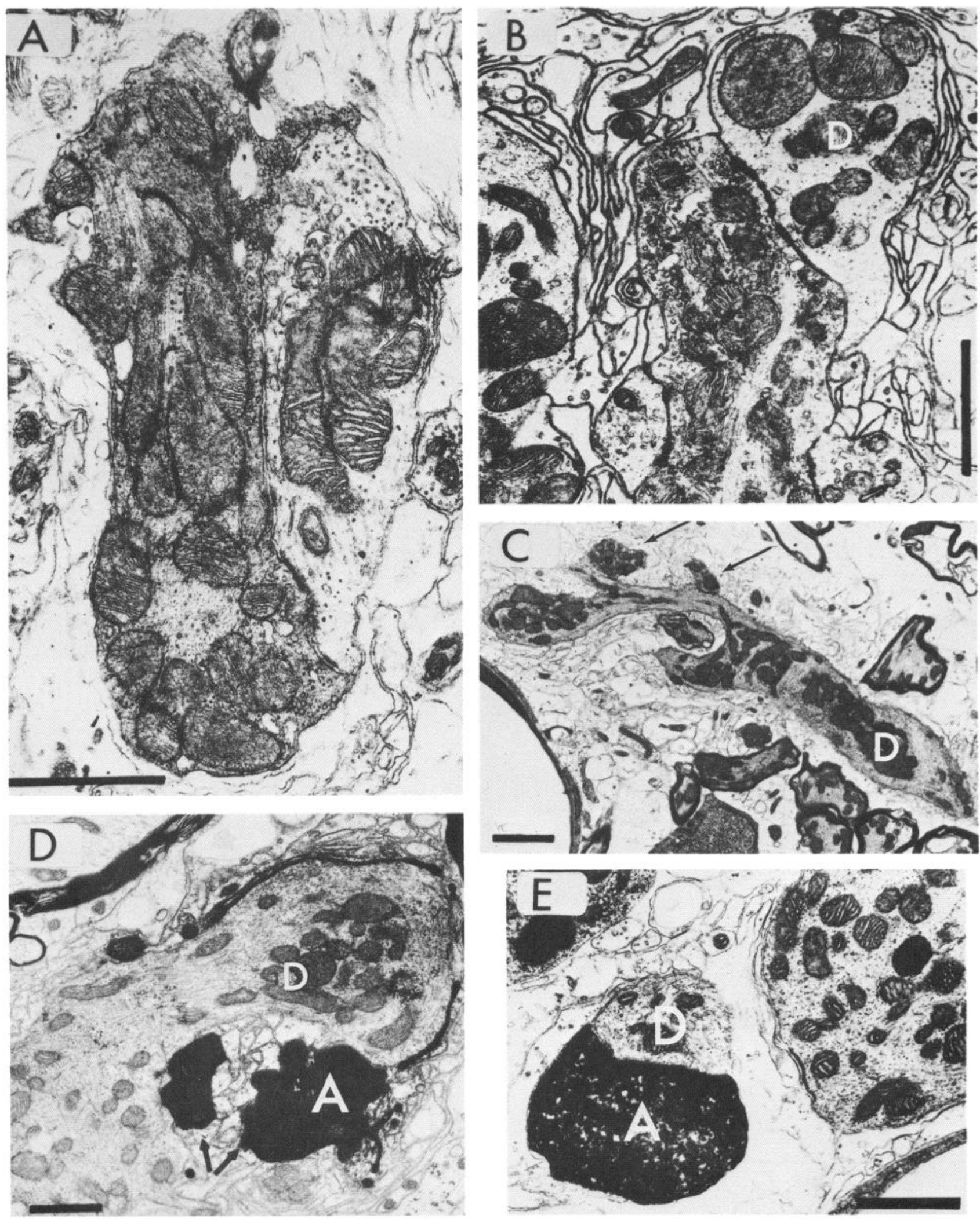

Figure 6. Synaptic islands. A, HRP-labeled terminal of an afferent axon contracting the swollen distal end of a small cell's dendrite (right). The light labeling permits visualization of chemical synapses with round vesicles, desmosomes, and gap junctions. When followed in serial sections, these synapses may continue for several micra, as if two cylinders were apposed on their long axis. Bar, $1 \mu \mathrm{m}$. $B$, Dendrite $(D)$ wrapped about an afferent axon. This second form of synaptic island synapse has a dendrite that twines about an afferent terminal (see Figs. $1 C$ and $5 E$ for other examples). Bar, $1 \mu \mathrm{m}$. $C$, A large extent of the swollen distal end $(D)$ of this small cell dendrite is visible. The two axon terminals that synapse on the dendrite are marked with arrows. Bar, $1 \mu \mathrm{m}$. D. A bizarre but not uncommon feature of the synaptic islands may be seen in this densely labeled afferent terminal. In addition to the terminals synapsing on the dendrite (arrows), the terminal membrane forms a sheet that wraps around the distal end of the dendrite. This wrapping may be seen leaving the large terminal to wrap around the dendrite $(D)$. Bar, $1 \mu \mathrm{m} . E$, Smaller version 

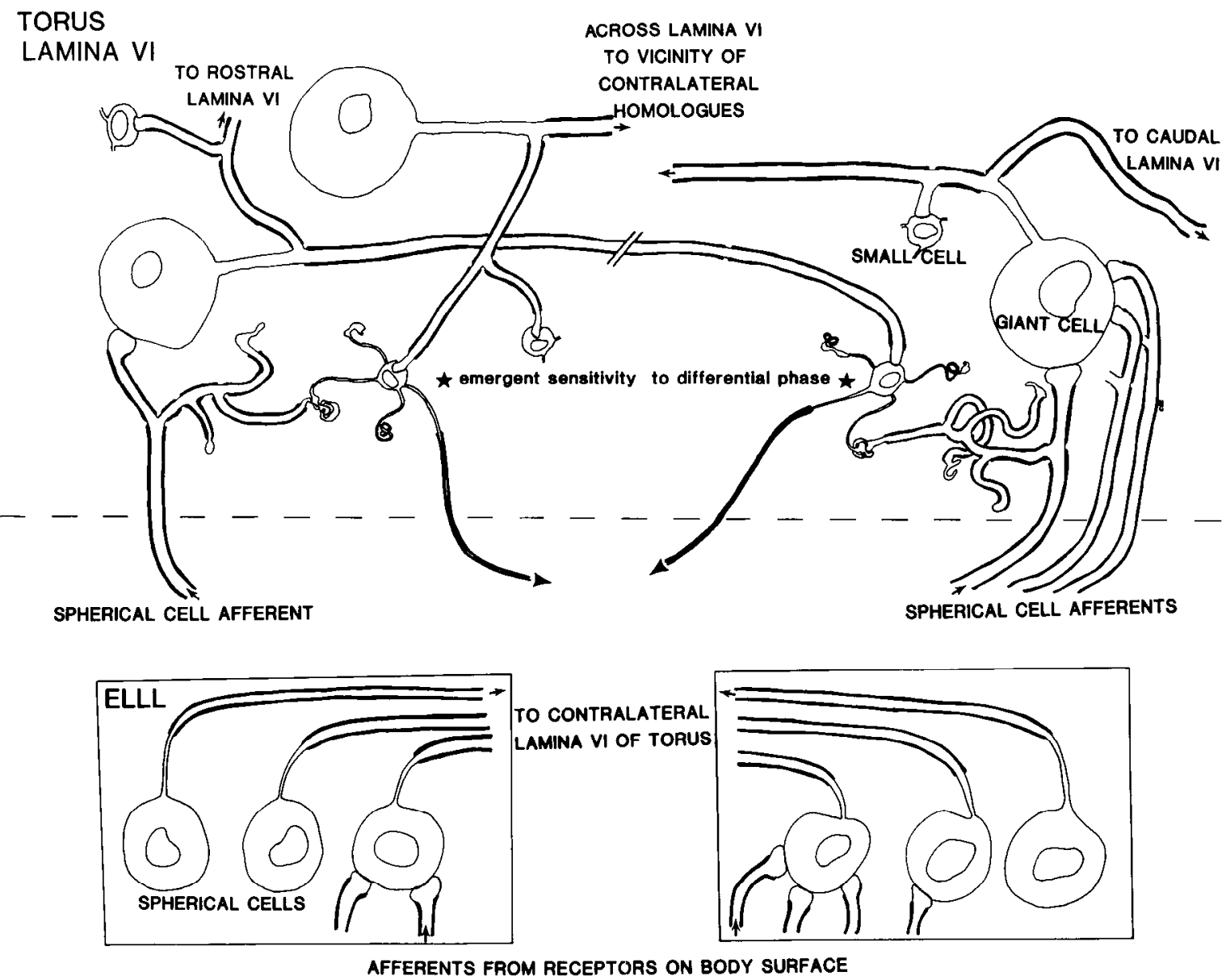

Figure 7. Summary of the cell types and connections of the phase comparison circuit of lamina VI: The morphological features underlying the sensitivity to small temporal disparities.

1985). We propose that the sensitivity of the small cells to small temporal disparities may be obtained by requiring that high levels of activity be optimally triggered by the simultaneous arrival of input from the soma and dendrites to the spike-initiating zone. The input to the dendrites would presumably arrive first and be delayed by some amount dependent on the dendritic morphology, while input to the soma would arrive at a time dependent on the location of the giant cell soma of its origin. Thus, all small cells compare a giant cell input against local afferent information, giving rise to sensitivity to temporal disparities between corresponding patches of the body surface.

The hypothesis that the detection of a small time difference between two signals may be mediated by the delay of the one input so that it arrives simultaneously with another is conceptually similar to the "place theory" proposed by Jeffress (1948) to explain mechanisms of sound localization. He proposed that delays might be provided by two afferent inputs of different lengths and/or conduction velocities, while we suggest that in lamina VI conduction delays are provided by dendrites of various lengths and thickness. We do not know if the small cells form a "place" or map of temporal disparities corresponding to space, such as is found in the auditory system (Sullivan and Konishi, 1986). We find somatotopic order in the afferent input to the dendrites, while the giant cell input to the somata appears to be chosen randomly. Somatopic order, however, is found in the laminae above and below Vl (Carr et al., 1981).

The morphology of the inputs to the small cells is so unusual as to suggest that structural specificities may at least partly account for their ability to detect small time differences, and that spatial separation of inputs may be the most important factor. This interpretation is comparable with that proposed for the auditory system of the chick by Parks and Rubel (1985). The site of binaural phase sensitivity in the bird is the nucleus laminaris, the cells of which also have an unusual morphology. Inputs from the ipsi- and contralateral ears terminate on the dorsal and ventral dendrites of the laminaris cells, respectively. This physical separation may reflect cellular requirements for the detection of simultaneously arriving inputs from different parts of the animal's sensory surface, in this case, the two ears. A similar separation may be observed in the "rabbit ear" cells of the mammalian medial superior olive, where input from the ipsilateral ear is found on one lateral dendrite and input from the contralateral ear on the other (Stotler, 1953). This spatial separation is provided in the phase-comparison system of $E i$ genmannia through having one type of input terminate on the soma, and the other on the distal dendrites.

The response pattern of the small cells may provide some indication of their mode of action (Heiligenberg and Rose, 1985). Their response over the periodic stimulus of the beat cycle [see Carr et al. (1986) for details of these stimulus regimes] rises 
from a low baseline of activity to $100 \%$ over a very small time window, about $40 \mu \mathrm{sec}$, after which their activity remains high. These responses suggest that some temporal order of inputs is necessary to cause the neuron to respond, and, conversely, that the opposite order is insufficient to excite the cell.

Because of the cyclical nature of the stimulus, when the small cell is not excited either the dendritic input or the giant cell input must occur first. If the giant cell input were to arrive first, the psp might invade the dendrites, blocking the dendritic input, and thus suppress the response of the small cell. A similar phenomenon has been observed in the control of vestibular nystagmus in the puffer fish: An antidromic spike in an oculomotor neuron blocks the response evoked by a dendritic spike, and this was presumed to invade the impulse-initiation sites in the dendrites (Korn and Bennett, 1975). At the neuron's preferred temporal disparity, the dendritic input and the giant cell psp would arrive in synchrony to fire the cell and might continue to excite it, as the potential change produced by the dendritic input would sum over the rising phase of the electrotonic giant cell psp as the one stimulus cycle scans through the other.

EM reconstruction of the synaptic islands suggests that the spatial requirements for synaptic input onto dendrites of small cells are such as to inject maximal amounts of current into the dendrites. These dendrites are from 0.5 to $1.5 \mu \mathrm{m}$ in diameter as they leave the soma, only swelling as they receive synaptic input distally (Fig. 5C). The large, and therefore low-impedance, distal swellings on these dendrites should facilitate current injection, while the insulation provided by glial and afferent axon wrappings surrounding them might ensure that much of this current flows into the thinner, more proximal portions of the dendrite. As the dendrite narrows toward the soma, its input resistance should increase, increasing the size of the psp. This resistance increase may be sufficient to produce a spike. This eventuality has been raised by Diamond and Ysargil (1969) and discussed in terms of dendritic spines by Jack et al. (1975). This would impose the requirement of excitable membranes in the small cell dendrites, but dendritic spikes have been observed in other systems (Korn and Bennett, 1975; Llinás and Yarom, 1980; Mori and Takagi, 1975; Schwartzkroin, 1975). A dendritic spike would have the advantage of not decrementing and thus injecting a greater amount of current into the soma. In addition, it would have a shorter time course, creating a more precise window of overlap between the dendritic input and the giant cell psp on the soma.

\section{Development of the time-comparison circuit}

The developmental assembly of the time-comparison circuit would require very few rules. Incoming afferents should contact anything but somata of small cells, and any giant cell could contact any small cell soma. The resulting combinations would be sensitive to all possible timing differences. Additionally, dendrites of small cells are of variable length; modification of dendritic length may provide a vehicle for fine tuning the system or compensating for growth.

The connections in lamina VI conform to the concepts of laminar and cellular specificity (Maler et al., 1981). Laminar specificity, where afferent inputs synapse on every postsynaptic target in a lamina, characterizes most laminated structures; in the case of lamina VI, it is exemplificd by sphcrical cell afferents that terminate on all possible postsynaptic sites (with the notable exception of the small cell bodies). The highly specific connectivity shown by giant cells, which synapse exclusively on small cell somata, and form their only synaptic input, has been termed cellular specificity (Maler et al., 1981).

The assembly of appropriate synaptic connections in lamina VI might be accounted for by the formation of cell-specific connections between the axon terminals of giant cells and small cell somata earlier in development than the appearance of lam- ina-specific connections made by spherical cell afferents. The afferents might terminate on any vacant postsynaptic site, and be out-competed at the small cell somata (Gottlieb and Cowan, 1972). Thus, the combination of cellular specificity in giant cell connections and laminar specificity in incoming afferents would be sufficient to produce the time-comparison circuit described above.

\section{Morphological specializations in the phase-coding system}

The morphology of the phase-coding system was first described by Rethelyi and Szabo (1973). Szabo and his coworkers identified lamina VI, which they termed the nucleus magnocellularis mesencephali, as an element of the fast, electrotonically coupled electrosensory system. Their light and ultrastructural studies on a number of gymnotiform fish identified the elements of lamina VI. A detailed study of Gymnotus carapo, a weakly electric fish with a pulse-type electric organ discharge (Sotelo et al., 1975) indicated that the midbrain phase-coding nucleus is very similar to lamina VI in Eigenmannia, despite the differences in their jamming avoidance response behavior, and the phylogenetic difference between pulse- and wave-type gymnotiform fish. Giant cells, small cells, and synaptic islands are common to both the pulse- and wave-species of gymnotiform fish, although some important differences exist between the two groups. In the pulsefish, Gymnotus carapo, giant cell somata are generally myelinated and do not possess a conventional initial segment. There are two types of small cells in both groups, but they receive morphologically distinct inputs in Gymnotus (Sotelo et al., 1975). The synaptic islands are extremely similar in both gymnotiform groups, sharing morphologically mixed synapses between dendritic profiles and axon terminals and copious glial wrappings. In consequence, it seems reasonable to propose that these axon terminals originate from afferent inputs in pulse-fish as well as Eigenmannia.

Both the phase-coding input and the time-comparison circuit in lamina VI are mediated by gap junctions. The advantage of added speed and accuracy in the long projections of the phasecoding system is apparent. The local circuit connections in lamina VI are also mediated by gap junctions. This may be due to both the system's ability to respond 1:1 with electric organ discharge rates from 200 to $700 \mathrm{~Hz}$, the species' range, and the giant cell's requirement for rapid transmission of timing information. This coupling also mediates synchrony in the response of individual spherical cells and giant cells to their convergent input (Carr et al., 1986).

The morphology of lamina VI may be characteristic of the fast electrosensory systems found in all weakly electric fish. Szabo et al. (1975) surveyed almost all gymnotiform genera and found the morphology and physiology characteristic of lamina $\mathrm{VI}$ in all cases. An active electric sense has evolved independently in the African Mormyriformes; these fish also have both phase- and amplitude-coding electroreceptors, and a similar midbrain nucleus, the nucleus exterolateralis mesencephali. The nucleus exterolateralis contains a dense network of axons with both giant and small cells and a projection from phase-coding cells in the medulla (Enger et al., 1976; Szabo et al., 1975).

The jamming avoidance responses of electric fish with pulseand wave-type electric organ discharges are very different, as wave-type fish adjust the frequency of their elcetric organ discharge so as to obtain a private frequency band, while pulsetype fish need private time intervals for accurate electrolocation (Heiligenberg, 1977). Thus, pulse-fish must act to minimize coincidences between the pulses of each fish. The similarities between the various midbrain phase-coder systems, despite the radical differences in the types of electrical signals processed, suggest that these connections may not have developed primarily for the jamming avoidance responses of these fish, but for the detection of phase shifts caused by the capacitive loads 
of objects (Heiligenberg and Rose, 1985). Behavioral and neurophysiological studies in both mormyriform and gymnotiform pulse-type electric fish are needed to explore functional correlates of the morphological similarities between pulse- and wavetype electric fish.

\section{References}

Bell, C., T. E. Finger, and C. J. Russell (1981) Central connections of the posterior lateral line lobe in mormyrid fish. Exp. Brain Res. 42: 9-22.

Boord, R. L., and C. A. McCormick (1984) Central lateral line and auditory pathways: A phylogenetic perspective. Am. Zool. 24: 765774.

Bullock, T. H., R. H. Hamstra, and H. Scheich (1972) The Jamming Avoidance Response of high frequency electric fish. I and II. J. Comp. Physiol. 77: 1-48.

Carr, C. E., and L. Maler (1985) A Golgi study of the cell types of the dorsal torus semicircularis of the electric fish Eigenmannia: Functional and morphological diversity in the midbrain. J. Comp. Neurol. 235: 207-240.

Carr, C. E., L. Maler, W. Heiligenberg, and E. Sas (1981) Laminar organization of the afferent and efferent systems of the torus semicircularis of gymnotiform fish: Morphological substrates for parallel processing in the electrosensory system. J. Comp. Neurol. 203: 649670.

Carr, C. E., L. Maler, and E. Sas (1982) Peripheral organization and central projections of the electrosensory nerves in gymnotiform fish. J. Comp. Neurol. 211: 139-153.

Carr, C. E., B. Taylor, and L. Maler (1983) Ultrastructure of a phasecomparison circuit in the midbrain of the weakly electric fish, Eigenmannia. Soc. Neurosci. Abstr. 9: 1028.

Carr, C., W. Heiligenberg, and G. Rose (1986) A time comparison circuit in the electric fish midbrain: I. Behavior and physiology. J. Neurosci. 6: 107-119.

Diamond, J., and E. N. Ysargil (1969) Synaptic functions in the fish spinal cord: Dendritic integration. Prog. Brain Res. 31: 201-209.

Enger, P. S., S. Libouban, and T. Szabo (1976) Rhombo-mesencephalic connections in the fast conducting electrosensory system of the mormyrid fish, Gnathonemus pertersii. An HRP study. Neurosci. Lett. 3: 239-243.

Gottlieb, D. I., and W. M. Cowan (1972) Evidence for a temporal factor in the occupation of available synaptic sites during the development of the dentate gyrus. Brain Res. 41: 452-456.

Heiligenberg, W. (1977) Principles of electrolocation and jamming avoidance. In Studies of Brain Function, Vol. 1, Springer-Verlag, New York.

Heiligenberg, W. (1980) The Jamming Avoidance Response in the weakly electric fish Eigenmannia. Naturwissenschaften 67:499-507.

Heiligenberg, W. (1983) The Jamming Avoidance Response in an electric fish: Algorithms in sensory information processing and their neuronal organization. In Advances in Vertebrate Neuroethology, J.P. Ewert, D. Ingel, and R. Capranica, eds., Plenum, New York.

Heiligenberg, W., and J. Bastian (1984) The electric sense of weakly electric fish. Annu. Rev. Physiol. 46: 561-583.

Heiligenberg, W., and C. E. Carr (1983) The torus semicircularis of gymnotoid electric fish: The functional organization of a parallel processor. Neurosci. Abstr. 155: 3.

Heiligenberg, W., and J. Dye (1982) Labelling of electroreceptive afferents in a gymnotoid fish by intracellular injection of HRP: The mystery of multiple maps. J. Comp. Physiol. 148: 287-296.

Heiligenberg, W., and G. Rose (1985) Phase and amplitude computations in the midbrain of an electric fish: Intracellular studies of neurons participating in the Jamming Avoidance Response (JAR) of Eigenmannia. J. Neurosci. 5: 515-531.

Jack, J. J. B., D. Noble, and R. W. Tsien (1975) Electric Current Flow in Excitable Cells, Clarendon, Oxford, UK.
Jeffress, L. A. (1948) A place theory of sound localization. J. Comp. Physiol. Psychol. 41: 35-39.

Korn, H., and M. V. L. Bennett (1975) Vestibular nystagmus and teleost occulomotor neurons: Functions of electrotonic coupling and dendritic impulse initiation. J. Neurophysiol. 138: 430-451.

Llinás, R., and Y. Yarom (1980) Electrophysiological properties of mammalian inferior olivary cells in vitro. In The Inferior Olivary Nucleus: Anatomy and Physiology, J. Corville, C. de Montigny, and Y. Lamarre, eds., pp. 379-388, Raven, New York.

Maler, L., E. Sas, and J. Rogers (1981) The cytology of the posterior lateral line lobe of high frequency weakly electric fish (Gymnotoidei): Dendritic differentiation and synaptic specificity in a simple cortex. J. Comp. Neurol. 195: 87-140.

Maler, L., E. Sas, C. E. Carr, and J. Matsubara (1982) Efferent projections of the posterior lateral line lobe in gymnotiform fish. J. Comp. Neurol. 211: 154-164.

Mori, K., and S. F. Takagi (1975) Spike generation in the mitral cell dendrite of the rabbit olfactory bulb. Brain Res. 100: 685-689.

Pappas, G. D., S. G. Waxman, and M. V. L. Bennett (1975) Morphology and spinal electromotor neurons and presynaptic coupling in the gymnotoid Sternarchus albifrons. J. Neurocytol. 4: 469-478.

Parks, T. N., and E. W. Rubcl (1975) Organization and development of the brainstem auditory nuclei of the chicken: Primary afferent projections. J. Comp. Neurol. 180: 439-448.

Rethelyi, M., and T. Szabo (1973) A particular nucleus in the mesencephalon of a weakly electric fish, Gymnotus carapo, Gymnotidae. I. Light microscopic structure. Exp. Brain Res. 17: 229-241.

Riley, J. (1979) A reliable Golgi-Kopsch modification. Brain Res. Bull. 4: $127-129$.

Scheich, H., T. H. Bullock, and R. Hamstra (1973) Coding properties of two classes of afferent nerve fibers: High frequency electroreceptors in the electric fish, Eigenmannia. J. Neurophysiol. 36: 39-60.

Schwartzkroin, P. (1975) Characteristics of CA1 neurons recorded intracellularly in the hippocampal in vitro slice preparation. Brain Res. 85: 423-436.

Sotelo, C., and H. Korn (1978) Morphological correlates of electrical and other interactions through low resistance pathways between neurons of the vertebrate central nervous system. Int. Rev. Cytol. 55: 67107.

Sotelo, C., and R. Llinás (1972) Specialized membrane junctions between neurons in the vertebrate cerebellar cortex. J. Cell Biol. 53:271289.

Sotelo, C., M. Rethelyi, and T. Szabo (1975) Morphological correlates of electrotonic coupling in the magnocellular mesencephalic nucleus of the weakly electric fish Gymnotus carapo. J. Neurocytol. 4: 587607.

Stotler, W. A. (1953) An experimental study of the cells and connections of the superior olivary complex in the cat. J. Comp. Neurol. 98 . 401-431.

Sullivan, W. E., and M. Konishi (in press) Generation of a neural place code for sound source azimuth. Proc. Nat. Acad. Sci.

Szabo, T., H. Sakata, and M. Ravaille (1975) An electrotonically coupled pathway in the central nervous system of teleost fish, Gymnotidae and Mormyridae. Brain Res. 95: 459-474.

Tokunaga, A., K. Akert, C. Sandri, and N. V. L. Bennett (1980) Cell types and synaptic organization of the medullary electromotor nucleus in a constant frequency weakly electric fish, Sternarchus albifrons. J. Comp. Neurol. 192: 407-426.

Triller, A., and H. Korn (1981) Interneuronal transfer of horseradish peroxidase associated with exo/endocytotic activity on adjacent membranes. Exp. Brain Res. 43: 233-236.

Wilson, C. J., and P. Groves (1980) A simple and rapid section embedding technique for sequential light and electron microscopic examination of individually stained central neurons. J. Neurosci. Methods 1: 383-391. 